\title{
Новиков И.С., Литау Н.В. \\ Автоматизированный анализ инвестиционно-производственного проекта по характеристикам горизонта планирования и стоимости единицы основных средств
}

Российский экономический университет им. Г.В. Плеханова Кемеровский институт (филиал) (Россия, Кемерово)

doi:10.18411/spc-8-12-2017-11

idsp: 000001:spc-8-12-2017-11

Инвестиционный анализ является отправной точкой для успешного развития любого предприятия. В нынешних кризисных условиях инвестиционный анализ приобретает особую актуальность и занимает одно из ключевых мест при экономическом анализе предприятия. Для успешных инвестиционных вложений нужно владеть научно-методологическими разработками, которые позволяли бы точно оценить эффективность инвестиционной деятельности предприятия, а в дальнейшем принять грамотные управленческие решения по их реализации. Изучение законов функционирования производственных предприятий сегодня трудно осуществить без использования автоматизированных информационных систем. В данной работе нами использован финансово-аналитический программный комплекс «Карма» [3]. Данный комплекс решает задачи оценки эффективности и выбора предприятием оптимальных объемов производства и финансирования на основе математических моделей, опубликованных в работах [1,2]. В пакет [3] заносится информация о проекте производства нескольких видов продукции. В частности, это стоимость единицы продукции, стоимостная оценка спроса на нее, стоимость единицы, производительность и срок службы основных производственных фондов (ОПФ), характеристики окружающей рыночной среды (горизонт планирования, ставка дисконтирования), а также ограничений на используемые производственные и финансовые ресурсы.

В пакете [3] мы имеем удобный функционал, позволяющий нам быстро и эффективно провести любое инвестиционное исследование, при этом получить наглядные графики и сделать соответствующие выводы.

Проведем с помощью [3] два вычислительных эксперимента по бизнес-проекту со следующими характеристиками (см. таблицу 1).

Таблииа 1

\begin{tabular}{|l|c|c|}
\hline \multicolumn{1}{|c|}{ Наименование параметра проекта } & Эксперимент №1 & Эксперимент №2 \\
\hline Количество видов продукции, шт. & 1 & 1 \\
\hline Ставка НДС, доля & 0,18 & 0,18 \\
\hline Ставка НИ, доля & 0,02 & 0,02 \\
\hline Ставка НП, доля & 0,2 & 0,2 \\
\hline Ставка СВ, доля & 0,3 & 0,3 \\
\hline Трудоемкость, доля & 0,25 & 0,25 \\
\hline Материалоемкость, доля & 0,3 & 0,3 \\
\hline Срок кредита, лет & 5 & 5 \\
\hline Ставка кредита, доля & 0,3 & 0,3 \\
\hline Максимальная сумма производителя, д.е. & 0 & 0 \\
\hline Максимальная сумма кредита, д.е. & 6000 & 6000 \\
\hline Максимальная сумма дотаций, д.е. & 10000 & 10000 \\
\hline Максимальная сумма инвестиций , д.е. & 1000 & 1000 \\
\hline Горизонт планирования, лет & $\mathbf{3 , 5 , 1 0 , 1 5}$ & $\mathbf{3}$ \\
\hline Ставка дисконтирования, доля & 0,3 & 0,3 \\
\hline Стоимость единицы ОПФ, д.е. & $\mathbf{2 0 0 0 0}$ & $\mathbf{2 0 0 0 0 , 5 0 0 0 0 , 7 0 0 0 0}$ \\
\hline Стоимость единицы продукции, д.е. & 28 & 28 \\
\hline Срок службы ОПФ, лет & 20 & 20 \\
\hline Производительность ОПФ, ед.пр/едОПФ & 5100 & 5100 \\
\hline Спрос на продукцию, д.е. & 100000 & 100000 \\
\hline
\end{tabular}




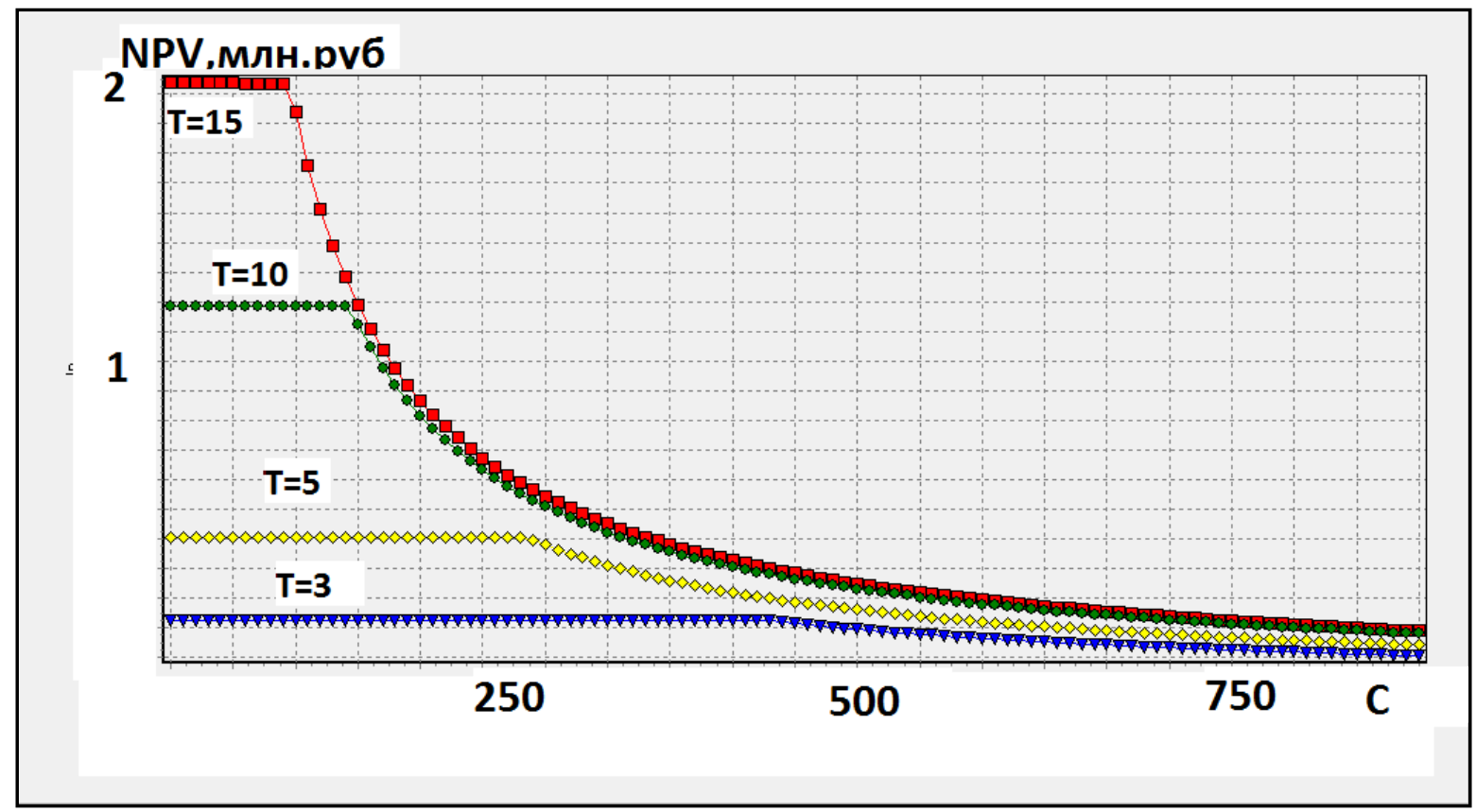

Pис.1 Зависимость NPV проекта от стоимости единиць ОПФ при варьировании горизонта планирования

На рисунке 1 представлен график зависимости чистой приведенной стоимости (NPV) проекта от стоимости единицы ОПФ (C) при варьировании горизонта планирования $\mathrm{T}=3 ; 5 ; 10 ; 15$. Очевидно, что с увеличением $\mathrm{T}$ эффективность проекта возрастает по абсолютной величине, а также увеличивается его устойчивость.

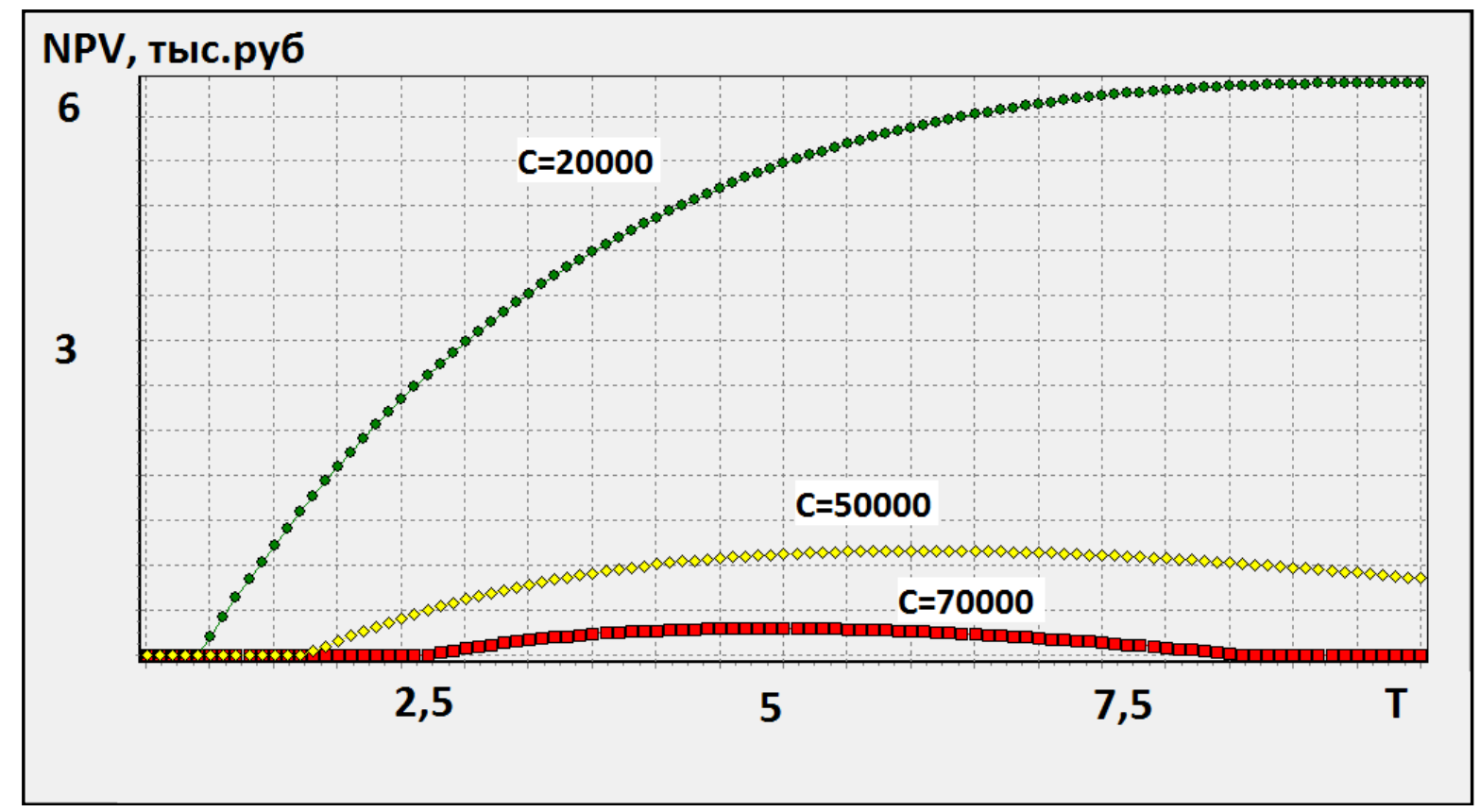

Pис.2 Зависимость NPV проекта от горизонта планирования при варьировании стоимости единищь ОПФ

На рисунке 2 представлен график зависимости NPV проекта от горизонта планирования при варьировании стоимости ОПФ, который позволяет оценить наглядно зависимость эффективности проекта от стоимости ОПФ при изменении параметра «горизонт планирования». В частности, при значениях $T k=20000 ; 50000 ; 70000$. Из данного графика можно, например, определить значения стоимости ОПФ, при которых проект перестает быть окупаемым. Кроме того, из графика определяется жизненный 
цикл (моменты, когда проект становится окупаемым и прекращает быть окупаемым), а также максимальные значения эффективности (NPV) проекта.

$$
* * *
$$

1. Медведев А.В. Оптимизационное планирование проектов функционирования экономических систем с заемным финансированием деятельности производителя // Фундаментальные исследования. 2016. - №9(2). - С.273-278.

2. Медведев А.В. Инструменты оперативного принятия решений при оценке эффективности бизнеспроектов // Международный журнал прикладных и фундаментальных исследований. - 2016. - №9-2. - C.182-186.

3. Конструктор и решатель дискретных задач оптимального управления («Карма») Программа для ЭВМ. Свидетельство о регистрации в Роспатенте №2008614387 от 11.09.2008. Правообладатели: А.В. Медведев, П.Н. Победаш, А.В. Смольянинов, М.А. Горбунов.

Прянишникова О.Н., Асанова И.Р. Налоговый учет основных средств

Российский экономический университет имени Г.В. Плеханова (Россия, Саратов)

doi:10.18411/spc-8-12-2017-12

idsp: 000001:spc-8-12-2017-12

В 2017 году налоговый учет основных средств компании осуществляют с учетом актуальных изменений законодательства. В статье будет раскрыто, как правильно отразить способы начисления амортизации и создания резерва в учетной политике, а также как учитывать расходы на ремонт основных средств.

Каждая организация должна иметь учетную политику в целях налогообложения, в которой отражаются те положения по налоговому учету, которыми будет следовать организация в тех случаях, когда законодательство предоставляет налогоплательщику возможность самому сделать выбор методов, способов учета и т.п.

Учетная политика не представляется в налоговую инспекцию при представлении бухгалтерской или же налоговой отчетности. Все же необходимо иметь в виду, если ИФНС всё же в ходе проверки потребует представить учетную политику, то это необходимо будет сделать в установленный срок:

1. В течении 5 рабочих дней со дня получения требования о представлении документов (п. 5 ст. 93.1 НК РФ) в следующих случаях:

- при проведении камеральной или выездной проверки другого налогоплательщика;

- вне рамок проверки для получения документов, касающихся конкретной сделки.

2. В течении 10 рабочих дней со дня получения требования о представлении документов (п. 3 ст. 93 НК РФ):

- при проведении выездной проверки организации или при проведении камеральной.

Порядок учета основных средств также находят свое отражение в налоговой учетной политике, а именно:

1. Методы начисления амортизации: линейный, нелинейный. Изменение метода начисления амортизации допускается с начала очередного налогового периода. С нелинейного метода на линейный метод начисления амортизации налогоплательщики имеют право переходить не чаще одного раза в пять лет (п. 1 ст. 259).

2. Создание резерва на ремонт основных средств и норматив ежеквартальных (ежемесячных) отчислений в него. Резерв можно создать (п. 3 ст. 260 НК РФ):

- на «текущий» ремонт основных средств; 